\title{
CRIANÇA E RELIGIÃO NO CINEMA BRASILEIRO: educação contemporânea
}

\author{
Wilton Garcia ${ }^{1}$
}

Resumo: Ao relacionar criança e religião no cinema brasileiro, o presente texto articula um posicionamento crítico-reflexivo a respeito da educação atual. Isso levanta uma pergunta: qual seria a diversidade que aproxima criança e religião no cinema nacional? Para exemplificar, os filmes selecionados foram Central do Brasil (1998) e Abril Despedaçado (2001), ambos de Walter Salles; Cidade de Deus (2002), de Fernando Meirelles e Kátia Lund; e Capitães da Areia (2011), de Cecília Amado. No formato ensaio, o percurso metodológico elege a pesquisa empírica, qualitativa, de observar, descrever e discutir sobre essas películas, a partir dos estudos contemporâneos. O resultado demonstra a potencialidade desses filmes para a produção de conhecimento atrelada à produção de subjetividade na educação contemporânea.

Palavras-Chave: Criança; Cinema Brasileiro Contemporâneo; Religião.

\section{CHILD AND RELIGION IN BRAZILIAN CINEMA: contemporary education}

Abstract: When relating child and religion in the cinema, this text articulates a critical-reflexive position about education nowadays. This raises a question: what would be the diversity that brings children and religion closer to national cinema? For example, the selected films were Central Station (1998) and Behind the Sun (2001), both by Walter Salles; City of God (2002), by Fernando Meirelles and Kátia Lund; and Sand Captains (2011), by Cecília Amado. In the essay format, the methodological course selects the empirical research, qualitative, to observe, describe and discuss about this movies, from the contemporary studies. The result shows the potential of these films for the production of knowledge linked to the production of subjectivity and, then, to the production of information.

Keywords: Child; Contemporary Brazilian Cinema; Religion.

\section{Introdução}

Segredo de ilê-axé a gente leva pra sepultura...

Povóas (2015, p. 340)

Na epígrafe deste texto, percebe-se a dimensão humana atrelada ao divino: a metáfora de um mito (HALL, 2016) olha para além do humano. Entre o sagrado e o profano (e vice-versa), guardar segredo fortalece o $a x e^{2}$. Daí surge o inexplicável para se assentar e, ao mesmo tempo, fazer girar a roda, em movimento, como metáfora de água de cachoeira que desce firme no rio; ou a estrada que abre caminhos; e, ainda, o vento que bate na copa da árvore - ninguém vê, mas sabe que esteve lá. Ou seja,

A expressão 'linguagem humana' designa a queda da divina 'linguagem em si', sua contaminação por toda a sujeira da inveja, da luta pelo poder e da obscenidade. E é fácil perceber em que sentido essa queda é acontecimental: nela, a estrutura eterna da linguagem divina vem a ser integrada ao fluxo acontecimental da história humana (ŽIŽEK, 2017, p. 40).

\footnotetext{
${ }^{1}$ Artista Visual, Professor do Programa de Pós-Graduação em Comunicação e Cultura da Universidade de Sorocaba (Uniso) e da Fatec Itaquaquecetuba, Líder do Grupo de Pesquisa Mídias Contemporâneas (MIDCON_), Doutor em Comunicação pela USP, e-mail: 88wgarcia@gmail.com.

${ }^{2}$ Nem sempre o que está dado no mundo pode ser exposto, de fato. O profundo fica em repouso, fechado.

$\mathrm{O}$ que se mantém velado permanece oculto e indica força, pois segredo conservado tem mais valor.
} 
A linguagem atravessa a cultura, ainda mais quando se tematiza criança e religião no cinema brasileiro. E cria uma abertura de deslocamentos necessários e, ao mesmo tempo, oportunos sobre diversidade: cultural, étnico-racial, religiosa, sexual etc. Ao relacionar criança e religião, nesse contexto, o presente texto articula um posicionamento crítico-reflexivo a respeito da educação contemporânea e pretende ampliar as discussões acerca dessa diversidade.

Isso levanta uma pergunta: qual seria a diversidade que aproxima criança e religião no cinema nacional?

Para exemplificar essa discussão, os filmes selecionados foram Central do Brasil (1998), escrito por João Emanuel Carneiro e Marcos Bernstein, e Abril Despedaçado (2001), adaptado do romance de Ismail Kadaré, ambos de Walter Salles; Cidade de Deus (2002), de Fernando Meirelles e Kátia Lund, adaptado do romance de Paulo Lins; e Capitães da Areia (2011), de Cecília Amado, adaptado do premiado romance de Jorge Amado. Com as categorias discursivas ${ }^{3}$ afeto, corpo e política identirária, o protagonismo infantil nessas películas nacionais (re)desenha uma perspectiva distinta sobre as coisas no mundo. São situações complexas que não se comparam ao comum.

São filmes brasileiros atuais que utilizam a produção audiovisual para se destacarem como produto educativo no processo civilizatório de nossa cultura (PELPART, 2013). Ao ilustrar a criança como protagonista, essas películas demonstram passagens na narrativa cuja religião bifurca o enredo cinematográfico. Portanto, momentos (re)veladores de decisão legitimam a continuidade de cada narrativa proposta a partir de perspectivas religiosas.

Para tal desafio de leitura, no formato ensaio, o percurso metodológico elege a pesquisa empírica, em um caráter qualitativo, de observar, descrever e discutir essas películas, cuja base teórico-conceitual efetiva-se a partir dos estudos contemporâneos (CANCLINI, 2016; EAGLETON, 2016; GUMBRECHT, 2015; HALL, 2016).

Diante de anotações e impressões da contemporaneidade, elegem-se territorialidades contundentes de produção de conhecimento e subjetividade. A formação do sujeito estimula a produção de conhecimento atrelada à produção de subjetividade. Do saber (teoria) ao fazer (prática), tais produções estimulam outros tipos

\footnotetext{
${ }^{3}$ Tais categorias auxiliam nesta proposição crítico-reflexiva que introduz a noção de diversidade (de opção, seleção, escolha e/ou preferência), entre práticas e saberes que conduzem à educação atual no Brasil.
} 
de produções, como: informação, imagem, digital ou de conteúdo para a internet (SODRÉ, 2014; VILLAÇA, 2018), entre outras.

Aqui, o formato ensaio flexibiliza o debate, relacionando emergências entre criança e religião no cinema brasileiro. Ensaiar implica recorrer a coordenadas entre reflexão e escrita para ressaltar polêmicas e desafios a serem superados. Definitivamente, o caráter científico de um ensaio considera-se como método para consolidar a leitura dos filmes, cujo rigor surge de critérios específicos e aprofunda o desempenho dessa empreitada, que aqui se dirige à educação contemporânea.

Ao discutir o ensaio como método, Canclini (2016, p. 53) afirma:

[...] fazer transdisciplina é uma tarefa política: ocupa-se o mesmo tempo do discurso, do sistema de evidências sensíveis que parece comum e dos modos de representá-lo, usá-lo para o controle social, criticá-lo e brincar com ele. A arte e as ciências sociais podem servir para o consenso que sustenta o poder de questioná-lo com objetivos diferentes. O que diferencia a arte? Talvez uma ênfase, um estilo.

Dessas premissas iniciais, o presente texto está composto por quinto partes principais: 1) Central do Brasil; 2) Abril despedaçado; 3) Cidade de Deus; 4) Capitães da Areia; e 5) Discussões. O primeiro tópico aborda a busca, quase que psicanalítica, pelo pai. No segundo tópico, a dor da perda que faz crescer. No terceiro tópico, ultrapassar a violência é uma (re)solução de si encontrar. O quarto tópico tangencia a estratégia do sincretismo das religiões brasileiras. O quinto tópico organiza um conjunto de diretrizes táticas que acentuam a discussão.

\section{Central do Brasil}

Entre criança, religião e cinema, a mediação de realidade e ficção garante uma discussão produtiva no processo de ensino-aprendizagem. Abrir as portas da imaginação para o afeto, através da imagem em movimento na grande tela do cinema, suscita um encantamento flexível e alternativo com os recursos estéticos e/ou técnicos de: profundidade, angulação, sonoridade, efeitos especiais, trucagens etc. Ser afetado pela magia do cinema faz parte do desenrolar da narrativa fílmica, mesmo que os operadores culturais não estejam tão em alerta - porque a formação de qualquer criança ou adulto está em um processo contínuo.

Em Central do Brasil (1998), de Walter Salles, João Emanuel Carneiro e Marcos Bernstein, um despertar convida o/a espectador/a a ser afetado pelo fascínio do 
desconhecido tratado, estrategicamente, como alegoria: simbólica e/ou emblemática. Ao se debruçar sobre essa fita, percebe-se a reminiscência dos protagonistas Dora (Fernanda Montenegro) e Josué (Vinícius de Oliveira). Essa reminiscência incorpora experiências vividas, na esperança de superar dificuldades e gerar novidades positivas. Seria buscar vestígios marcantes do afeto, nas memórias e nas lembranças, que contribuem para decisões futuras. Como ato sublime de resignação - entre a solidariedade, o respeito e a dignidade humana, essa reminiscência serve de operador cultural para alcançar o objetivo proposto no início da narrativa: retornar para casa, em busca do pai.

A sinopse sinaliza:

Dora, uma amargurada ex-professora, ganha a vida escrevendo cartas para pessoas analfabetas, que ditam o que querem contar às suas famílias. Ela embolsa o dinheiro sem sequer postar as cartas. Um dia, Josué, o filho de nove anos de idade de uma de suas clientes, acaba sozinho quando a mãe é morta em um acidente de ônibus. Ela reluta em cuidar do menino, mas se junta a ele em uma viagem pelo interior do Nordeste em busca do pai de Josué, que ele nunca conheceu.

No discurso fílmico, a imagem urbana do Rio de Janeiro entrelaça-se à violência da desigualdade social, mediante a precariedade vivenciada pela população mais pobre com atropelos terríveis diante da baixa qualidade, ou falta, cotidiana de transporte, trabalho, moradia, e/ou saúde. Ao expor uma crítica aos grandes centros urbanos do país, a obra explora o (des)encontro da criança (Josué) com sua família: a perda da mãe acidentalmente, a solidão de estar perdido na Cidade Maravilhosa, sem seus irmãos mais velhos, inclusive sem o pai desconhecido.

Então, Dora acompanha Josué na viagem de ônibus para o Nordeste brasileiro. Nessa saga, tentam juntos arrumar suas vidas da melhor maneira possível: ela deseja fazer o bem; já ele deseja apenas uma família. Durante esse drama, ambos compõem uma carga afetiva de conflitos, enfrentamentos, (des)encontros, proteção, (re)ajustes e (des)acordos. À dor de Dora equivale o sentimento de esperança do garoto, cuja simplicidade perpassa pela emoção que aflora. Esse, talvez, seja o maior desafio no processo de ensino-aprendizagem, nessa história, pois quando se espelha na narrativa cinematográfica sobre um menino perdido na multidão urbana coloca-se no lugar dele para agenciar/negociar a incessante procura de um lar - a família e o pai.

Dora envolve-se com Josué, como relação de mãe e filho, em que as condições adaptativas do sujeito ambientam sua extensão afetiva - na expectativa de consolidar 
um ato de amor. Indiscutivelmente, entre ficção e realidade (e vice-versa), há uma cena instigante quando a criança adormece na rua sob os braços da mulher adulta, remetendo à famosa cena da Pietá. Michelangelo esculpiu Jesus morto nos braços da Virgem Maria, mas aqui é Dora que acolhe Josué, em uma citação paródica - do sagrado ao profano. No entanto, o filme exibe rupturas com uma troca de papéis, pois ao amanhecer é Josué que apoia a cabeça de Dora. Portanto, a atenção que um tem para com o outro tece o desenrolar da trama.

O filme Central do Brasil é um road-movie - filme de estrada - porque a aventura acontece, na verdade, durante a viagem do Rio de Janeiro ao Nordeste. A vagar pela estrada, o caminho desse retorno é feito de lembranças e esquecimentos, em que o (des)apego elege a natureza humana. Nessa peregrinação, atravessam histórias difíceis de gente humilde, como eles. Também, a lógica da narrativa aprofunda um tecido revelador do Brasil profundo, em que a imagem da procissão católica de devotos em romaria de uma vigília noturna ao carismático Padre Cícero traduz o sentido da esperança para a simplicidade dos desvalidos.

No fundo, o discurso fílmico constitui uma tônica forte, na intensidade da experiência contemporânea (GUMBRECHT, 2015), ao retratar paradoxalmente as mazelas do Ser Humano. Como ato sublime de resignação - entre a solidariedade, o respeito e a dignidade humana, essa resignação parte de Dora por Josué, mas também na devolutiva dele, diretamente, atento para com ela. Ambos sofrem e se divertem juntos, como criança e adulto. Do perfil que se projeta, perante o testemunho do público, a narrativa fílmica permite que o/a espectador/a desfrute de uma aproximação especial dos/as personagens, cujas recordações imprimem os novos passos a serem dados.

\section{Abril Despedaçado}

O que encanta em um filme é sua própria capacidade inventiva de criar uma ficção para nossa vida, inclusive tendo como parâmetros as diretrizes educacionais contemporâneas. O protagonismo infantil na película brasileira exemplifica inquietudes, em que a criança se torna o centro do debate. Sendo assim, o cinema serve como potente instrumento no processo de ensino-aprendizagem. Discutir personagens e narrativas cinematográficas na educação atual, por exemplo, ajuda a questionar a vida cotidiana, visto que ilustra a condição humana. 
Em Abril Despedaçado (2001), de Walter Salles, adaptado do romance de Ismail Kadaré, as (des)territorialidades dos/as corpos agenciam/negociam suas próprias noções de diversidade, em que se constatam limites morais e éticos. Tais limites provocam a produção de subjetividade desses/as personagens. Ou seja, a sensibilidade vislumbra momentos agudos que precisam se defender de estranhos e evitar desconforto e/ou insegurança. Evidências sensíveis levam à indulgência do Ser Humano, que reconhece e respeita o valor humano.

A sinopse anuncia:

Em 1910, Tonho vive com sua família no sertão brasileiro. O seu pai tenta convencê-lo a vingar a morte do irmão mais velho, assassinado por uma família rival, mas sabe que caso se vingue será perseguido e terá pouco tempo de vida. Angustiado pela perspectiva da morte, Tonho passa a questionar a lógica da violência e da tradição.

Essa narrativa cinematográfica desperta indagações de Pacu (Ravi Ramos Lacerda), sua dubiedade e seu medo, na atmosfera quase "medieval" do sertão brasileiro. Ele é uma criança encantadora e ingênua de dez anos, o mais jovem dos três filhos da família Breves, que vive, exclusivamente, do plantio da cana de açúcar e enfrenta dificuldades. A vida para essa família resume-se à lida exaustiva do ciclo do plantio, corte e processamento da cana, no interior do Brasil. O pai orgulhoso (José Dumont) é um patriarca severo, sisudo, pois o trabalho duro e a estrita obediência devem ser cumpridos por sua ordem rígida.

No começo da narrativa, numa rara quebra na rotina diária da família, Pacu segue feliz, em meio a um canavial aberto, montado sobre os ombros do irmão mais velho, Inácio (Caio Junqueira), numa extensão visual formando um grande corpo forte. Quem sabe, essa corporeidade será explorada, aos poucos, na vazão de novos atropelos familiares de morte e vingança.

Porém, como ironia do destino, em um campo aberto (plano geral), Inácio é baleado e morto de repente. Uma morte besta. Findo o período da trégua obrigatória, seu pai enfurecido envia o filho do meio, Tonho (Rodrigo Santoro), que tem a missão de vingar a honra da família. Como ordem patriarcal, descortina-se uma violência brutal no pedido de vingança. O pai diz: "você sabe o que você tem que fazer?!"

A tensão do personagem Pacu destaca a intensidade de participação, pertença e presença (GUMBRECHT, 2015), pois aborda o modo de ser do homem sertanejo, revelando que tem a palavra como o seu maior bem precioso; tão distinto. $\mathrm{O}$ fervor 
religioso intenso da família precisa ser revisto/relido. $\mathrm{O}$ anjo cor de jambo, com sua astúcia cativante, sensibiliza o/a espectador/a, o/a qual se identifica com a perspectiva mais trágica: a criança escolhe a morte para salvar Tonho. A amizade de ambos mostra o sacrifício como uma solução. O desejo do menino, Pacu, resiste ao poder, pois não quer que o irmão morra.

O filme está montado em torno de uma estrutura dialógica entre a terra e o céu, entre a ordem instituída pelo patriarcado e a desordem infantil do menino. De fato, os personagens estão aprisionados no trabalho estafante da bolandeira de fazer açúcar e o voo dos jovens no balanço, na corda. Essa bifurcação (re)dimensiona contradições e (des)encontros.

Já a presença das rezadeiras, nessa narrativa cinematográfica, anuncia cantos ancestrais, para encomendar os mortos, celebrando os que partiram no momento do velório. Vozes semelhantes funcionam como coro de choro, lamento e sofrimento. Seria uma forma de conservar o ritual no canto fúnebre pronunciado por gemidos e murmúrios. A integração dessas rezadeiras, no filme, parece não ter sido aleatória, pois a tragédia anunciada prolonga a ritualidade da dor, que permanece.

Descortinada pela voz infantil de Pacu, tal película navega entre a fábula, a lenda, a anedota e a tragédia. Nota-se que o filho caçula dos Breves é o único membro de ambas as famílias a manifestar o desejo de que essa guerra, sem sentido, tenha fim. Com a imaginação e o sorriso, Pacu evoca transformações inigualáveis e cria uma recorrência de dinâmicas estratégias. E, até mesmo, a ingenuidade de Pacu é relativa, porque às vezes compreende a vida muito mais do que os adultos. O personagem descontrai a trama, enredada em tristeza e tensão. Parece ser o mais lúcido da família, ainda que soubesse sonhar, morreu vivenciando a dura realidade de um mundo que se perde em círculo. O carisma do personagem é eliminado por presteza e devoção ao irmão e o desafio à tirânica autoridade paterna. Assim, Pacu opõe seu desejo à existência da vida.

\section{Cidade de Deus}

Na sociedade contemporânea, a urgência da diversidade (cultural, étnico-racial, religiosa, sexual etc.) - entre alteridade e diferença - divide extremos enunciativos de aspectos econômicos, identitários, socioculturais e/ou políticos (EAGLETON, 2016; GIANNETTI, 2016; HALL, 2016). A diversidade dispõe o sujeito e sua sujeição 
(inter)subjetividade, ao valorizar suas (dis)junções. Mais especificamente, as dinâmicas estratégicas da diversidade, no Brasil, fomentam a agenda de debates na formação do sujeito contemporâneo (SODRÉ, 2014; VILLAÇA, 2018). Na medida em que a experiência depende da produção de intensidade sobre o sujeito, as relações humanas diversificam sua produção cultural.

No filme Cidade de Deus (2002), de Fernando Meirelles e Kátia Lund, adaptado do romance de Paulo Lins, o protagonismo está por conta de crianças e adolescentes com suas peripécias e escolhas inusitadas. Sem dúvida, assiste-se a uma película pautada pela intensidade da experiência (GUMBRECHT, 2015), cuja inocência vincula-se ao amadurecimento imediato.

A sinopse assegura:

Nas favelas do Rio de Janeiro dos anos 1970, dois rapazes seguem caminhos diferentes. Buscapé é um fotógrafo que registra o cotidiano violento do lugar, e Zé Pequeno é um ambicioso traficante que usa as fotos de Buscapé para provar como é durão.

Um jovem pobre quer estudar e ser um fotógrafo, já o outro quer virar bandido. Os dois são frutos de uma sociedade decadente, com enorme ausência de oportunidade. Nesse cenário, a falta de políticas públicas é devastadora. A violência urbana na favela do Rio de Janeiro torna-se documentada pela ficção cinematográfica que aponta para a miséria nacional. A favela expressa a marginalização da desigualdade econômica, no país, ao (re)inscrever problemas sociais na película, a partir do olhar de Buscapé. Como narrador de atrocidades, o menino testemunha acontecimentos singulares de projeção e identificação - entre o claro/escuro da tela de cinema.

Destaque para um garoto audacioso, vulgar, crítico e violento, que quando criança era Dadinho seu apelido, mas, ao crescer passou a imperar na favela como Zé Pequeno. O personagem comete assaltos e crimes inescrupulosos realizando ações inumanas. Ou seja, traz consigo a dor da miséria e o desejo constante de poder na favela.

Intenso na sua performance irracional, Zé Pequeno foi capaz de matar até a família e alguns amigos. E responde, externamente, a algumas frustrações pessoais: não tem amigos, além do Bené, que morre no baile; não tem garotas e nem sabe dançar. A transferência desses fracassos remedia-se com acessos súbitos de violência. Contra o mundo e contra todos, tem sede de vingança da vida. As atitudes odiosas são degenerativas como suas feições obscenas. O resultado que reitera essa dramatização: 
os policiais tomaram seu dinheiro; alcançou a morte com tiros nas costas, executado pelas crianças que ele mesmo deu as armas. Mas, não prestou atenção que eram garotos vingando a amizade deles com outro traficante do morro: Sandro Cenoura.

Todavia, há uma cena especial do grupo de bandidos intitulado Trio Ternura (Alicate, Cabeleira e Marreco). É um bando de ladrões que viviam de pequenos furtos e assaltos, tocando o terror na favela, logo no início da construção do conjunto habitacional Cidade de Deus, nos anos 1960. Então, invadem o motel da região e levam a criança valente Dadinho (que mais tarde virou Zé Pequeno), para ficar de tocaia e ser o vigia da emboscada. Porém, o garoto assassina clientes e trabalhadores e o grupo é perseguido pela polícia, em razão disso.

Para fugir do crime, Cabeleira corre para a casa da namorada e tenta se esconder. Mas é morto pela polícia no outro dia cedo, tentando escapar do bairro. Alicate e Marreco passam a noite dependurados em uma árvore, escondendo-se da varredura da polícia. No meio dessa turbulência, ao amanhecer, Alicate diz para Marreco que teve uma visão mística: uma gota de água deslumbrante caiu da árvore, mas não atingiu os policiais. Isso fez com que ele se arrependesse do que fez de errado na bandidagem e decide voltar para a igreja evangélica.

Essa passagem parece ser reveladora na lógica da transformação humana. Ao deixar escapar idiossincrasias da natureza, essa intensidade da experiência acumula informação, ainda que gere elementos surpreendentes, os quais produzem efeitos. Esse último coloca-se distante da produção de sentido: o que impacta o sistema capitalista, a almejar uma posição contra hegemônica.

Para o processo de ensino-aprendizagem, lidar com essas questões - de violência e desigualdade social - requer enfrentar a realidade com cautela. Aspirações dinâmicas entrecruzam variantes recursivas com predicações estratégicas. Metamorfoses, rapidamente, modificam a composição da informação como argumento contundente a ser estudado. Vislumbram-se provocações conceituais e "novas/outras" esferas discursivas a serem investigadas cada vez mais.

\section{Capitães da Areia}

Água, flor e o mar. Assim começa o filme Capitães da Areia (2011), de Cecília Amado, adaptado do premiado romance de Jorge Amado. Nele, a escritura do divino religioso, sincreticamente, amplia a dinâmica estratégica da diversidade enquanto 
necessidade da expressão humana, em particular a desigualdade social e a violência (PELPART, 2013). Esse sincretismo religioso (cultural) agencia/negocia misturas entre a Igreja Católica, o Candomblé e a Umbanda, entre outros, no Brasil. Sem a intenção de denúncia ou vitimização, a religião tange os/as personagens nessa narrativa ao garantir algumas (re)formulações da sociedade atual para com o/a Outro/a.

A sinopse indica:

Pedro Bala, Professor, Gato, Sem Pernas e Boa Vida são adolescentes abandonados por suas famílias, que crescem nas ruas de Salvador e vivem em comunidade no Trapiche. Eles praticam uma série de assaltos e são constantemente perseguidos pela polícia. Um dia, Professor conhece Dora e seu irmão Zé Fuinha e os leva até o Trapiche, o que desencadeia a excitação dos demais garotos, que não estão acostumados à presença de uma mulher no local. Aos poucos, nasce o afeto entre $o$ líder do grupo e a jovem.

Essa narrativa fílmica inicia e termina com uma cena intrigante para se pensar sobre criança e religião no cinema. No prólogo, assim como no final, verifica-se a famosa procissão dos devotos de Yemanjá, na região do bairro do Rio Vermelho, localizado na cidade de Salvador, no estado da Bahia. Do sagrado ao profano (e viceversa), é uma festa alegre e divertida com música, dança e comida, em que crianças tomam banho de mar, enquanto alguns tocam instrumentos dançam e cantam. Além disso, todos/as cantam, dançam, tocam tambores para animar a festa e fazem orações para reverenciar essa mãe d'água.

Flores são lançadas no oceano como oferenda à Deusa do Mar, enquanto alguns caminham pela areia da praia. Com isso, a festança acontece com a imagem de uma Sereia carregada no andor como santa. Elemento mítico do mar e dos pescadores, metade mulher, metade peixe, de dorso nu e rabo em calda azul, esse Orixá feminino que na igreja católica brasileira seria reconhecida e sincreticamente santificada - é reverenciado por um enorme grupo de pessoas que caminha pela orla marítima até as águas da praia, onde ficam as embarcações. Entregam presentes, como: flores, espelhos, retratos perfumes, guias, pentes etc. Também, as Mães de Santo baianas dão banho de pipoca, acendem velas e batem folhas nas pessoas para se purificarem. Fazem pedidos e agradecimentos de proteção à Rainha do Mar.

Dessa forma, determinada ritualidade religiosa do Candomblé explora o movimento de parcelas que devem ser cumpridas, conforme a solicitação e/ou a necessidade. E, nessa cena, a criança aprende com os adultos o significado da devoção à 
Yemanjá, um ritual religioso bastante tradicional no país. De modo geral, a criança acredita no que lhe é ensinado. Sem dúvida, a criança na tela do cinema apre(e)nde o ensinamento cultural, religioso etc. Seja a criança como operador cultural do cinema, em casa com a família, no bairro ou, ainda, na sala de aula, ela vivencia determinada experiência, tendo o modelo de representação a ser descortinado por suas próprias indagações. Portanto, o acesso à informação torna-se relevante para que a criança ou o adolescente saiba discernir o que se oferece, de fato.

Retomando à narrativa fílmica, uma peculiaridade no momento da procissão acontece quando os fiéis transportam a Santa em direção ao mar. No início do filme, a imagem sagrada de Yemanjá, carregada em um andor enfeitado de rosas brancas, é de gesso e pintada de branco e detalhe azul, com um colar (uma guia) no pescoço. Porém, já no final dessa narrativa, há uma troca para outra imagem de Yemanjá, esculpida na madeira escura, como ébano. Do claro ao escuro (e vice-versa), talvez isso sirva de experimentação poética da proposta fílmica que se adapta à literatura do escritor Jorge Amado para que o enredo possa simular o deslocamento de espaço-tempo como percurso vivenciado pelos/as personagens.

Também, existe uma cena no final da trama na qual Dora, a protagonista, que faz par com Pedro Bala, está acamada no hospital de freiras. Enferma, a menina necessita de cuidados hospitalares. No entanto, o herói força a retirada da garota dos cuidados médicos e solicita ajuda à sua Mãe de Santo que, com humildade e sabedoria, evoca cânticos da cultura ancestral africana. Essa canção, repetidamente entoada, serve para reiterar sua purificação a partir da ancestralidade. É um pedido de limpeza.

Sara nyenye bokonon

Sara nyenye eûे

Com folhagem seca nas mãos que corre o corpo da garota, Mãe Aninha benze com sua sabedoria segredada no fundamento do culto do Vodun - ritualizado na tradição fon, como no Candomblé brasileiro ou na Santeria cubana. Depois, utiliza-se uma pomba branca para que a paz retorne. No domínio da cura e da palavra, Bokonon possui amuletos e como sacerdote constitui a vitalidade de um/a farmacêutico/a aquele que detém poder de decisão em seu reino. Lamentavelmente, a dor de Dora foi amor que não resistiu. Conheceu o amor de Pedro Bala, mas precisou partir cedo. 


\section{Discussão}

A educação contemporânea tem, sim, a oportunidade de resgatar valores e ampliar as possibilidades do viver em sociedade. Além disso, educar experimenta variantes de alteridade, diferença e diversidade, para ampliar a visão da criança com as alternativas mais plausíveis. Educar, dessa forma, almeja considerar que a informação possa ser recolhida de diferentes dispositivos, instrumentos, ferramentas ou aparelhos, como o cinema. Para além de uma perspectiva pós-colonial, são experiências profundas nesse processo de formação do sujeito que se (re)organizam na contramão do sistema hegemônico e devem ser amparadas pelas suas dinâmicas dissidentes.

De acordo com Pelbart (2013, p. 119):

Do ponto de vista das figuras que comandam o pensamento e a subjetividade ocidental, quer se trate do Ser, do Bem, da Ideia, de Deus, do Eu, da Razão, do Significante, do Édipo, do Estado, do Capital, estamos às voltas sempre com modalidades de rebaixamento ou negação da diferença, com doses maiores ou menores de transcendência, vingança, nivelamento, vazio.

Atento ao pensamento e à subjetividade, é interessante (re)considerar a crença, a fé, a religiosidade e o querer de cada Ser Humano, ao acreditar em algo que transcende e, provavelmente, seria tão relevante como o alimento da alma, do espírito e do corpo na expectativa de ampliar o que necessita estar além. De modo indiscutível, o que vale nessas leituras crítico-reflexivas não são as interpretações dos eventos/acontecimentos, mas a produção de efeito causada pela ficção - da literatura ao cinema (e vice-versa). Esse estado de ficcionalidade serve como modelo social para se refletir a respeito da criança no encontro com a religião, aqui destacada no universo cinemático.

Em Central do Brasil (1998), a visão simplista do protagonista infantil, Josué, desespera na procura pela casa e pelo pai. Ou seja, a criança almeja o aconchego, conforme e segurança dos seus, pois ainda depende desse amor incondicional, fraternal, para avançar na vida e descobrir seu caminho. O que repousa a condição adaptativa do afeto a ser conquistado está na peregrinação religiosa dos romeiros, que tangencia a força recorrente na cultura popular brasileira. Essa passagem é atravessada por Dora e Josué.

Já em Abril Despedaçado (2001), a escolha da morte eleva Pacu para uma (re)dimensão (inter)subjetiva, quando escolhe salvar o irmão. Sua ingenuidade permite fazer esta escolha, sem medir as consequências. Como modelo da condição humana, talvez, a relevância da criança está em preservar a vida do fraterno, mesmo que para 
isso se submeta ao sacrifício de defendê-lo.

No filme Cidade de Deus (2002), a violência de assaltantes e bandidos na favela transfere-se para uma espécie de ressurreição, em que o jovem Alicate decide abandonar o crime, depois de passar um grande aperto, sendo perseguido na mata fechada, e vai viver o evangelho. Para obter a chance de se (re)considerar a produção de afeto em sua (re)dimensão (inter)subjetiva, a força da maldade cede lugar ao encontro com a epifania do divino, em que as normas estabelecem um caminho do bem.

Por último, Capitães da Areia (2011) tematiza o amor juvenil e a mística sincrética que permeia os valores mais profundos da cultura afro-brasileira como suporte de uma realidade cruel. A ingenuidade da criança, que acredita na salvação divina, promove a possibilidade de recuperação e cura, através de determinada ritualística do Candomblé. Junto a isso, a entrada e a saída dessa narrativa cinematográfica contêm mudanças contundentes, que iluminam o sincretismo religioso e cultural brasileiro.

Ao debruçar linguagem e presença Gumbrecht (2016, p. 27-28) propõe:

A experiência mística e a linguagem do misticismo são o meu quarto paradigma. Por meio de uma referência constante à sua própria capacidade de interpretar a presença intensa do divino, a linguagem mística produz o efeito paradoxal de estimular imaginações que parecem fazer esta mesma presença palpável. [...] em vez de tomar literalmente essas formas de expressão como a descrição de alguma coisa, ou seja, de uma experiência mística que realmente excede os limites da linguagem, uma visão secular e analítica compreenderá a experiência mística em si como um efeito da linguagem e dos seus poderes inerentes de autopersuasão.

A experiência mística transcende nossos valores e a educação contemporânea necessita (re)considerar seus próprios parâmetros e diretrizes, sobretudo no Brasil. Portanto, intensificar questões ligadas à diversidade é mais rico quando a linguagem de tal diversificação enumera preferências distintas, que (re)adequam o contexto da sociedade atual. O que desperta instabilidades críticas e descompassos para (re)calcular as propriedades humanas, baseando-se na discordância de dados estratificados pelo teor ético e moral.

Diante da crise da cultura, no livro A morte de Deus na cultura, Eagleton (2016, p. 120) assegura:

A cultura pode funcionar como uma crítica do capitalismo industrial, mas se mostra igualmente desdenhosa das forças que o desafiam. A política radical denuncia a motivação do lucro ou dos privilégios da aristocracia, mas a cultura entende o papel que desempenham na diversa 
totalidade da existência humana. É, em suma, uma espécie de fatalismo imbuído de altos ideais, sereno de sua convicção de que tudo tem seu lugar. Como tal, é também uma forma de teodiceia.

Ou seja, a existência humana se justifica entre o bem e o mal. Como o alto ou o baixo, isso requer observar o que seria aproximar - e/ou se distanciar - do objetivo proposto, em cada atividade educacional. Portanto, uma atividade educativa (didáticopedagógica) perfaz a lógica combinatória de qualquer ritualística religiosa em que se convida a participação do/a Outro/a. Há situações complexas que não se comparam ao comum, ao comunitário ou, ainda, à comunicação em si. Porque se articula entre o sujeito e sua coletividade.

Do ponto de vista político, as minorias agenciam/negociam suas expressões contemporâneas de alteridade, diferença e diversidade. Assim, parecem ser profícuas as chamadas minorias, que se multiplicam e reforçam seu empoderamento de informações, imagens etc. Ao aproximar o universo infantil do religioso, tendo o cinema brasileiro como dispositivo estratégico, a educação necessita de profundas revisões para agenciar e negociar com "novos/outros" práticas e saberes. A outridade escapa de referentes comuns (do que está previsto para além de), ao demonstrar a fragilidade de qualquer relacionamento na condição adaptativa da diversidade. Esta última compreende uma virtude em si mesma como vicissitude, ao solicitar a atenção e seus vasos comunicantes, os quais propagam características de si (re)ativadas na relação para com o/a Outro/a.

\section{Considerações finais}

Segredo bom não serve para ser relevado. Da intimidade à privacidade, não há imaginação que o cerque para preservar confidências. Nesse leque de discussões, por ora, os filmes abordados apresentam uma ideia de diversidade que aproxima criança e religião no cinema nacional. Mais que isso, a diversidade propicia pluralidade, ao mesclar múltiplas combinatórias entre o Catolicismo, o Candomblé, a Umbanda, o Protestantismo, bem como outras tantas práticas e saberes religiosos.

Ter a criança como personagem nessas narrativas cinematográficas, ao extrapolar a realidade com a ficção, traduz a dinâmica estratégica de projeção e identificação. Entre realidade e ficção, o cinema manifesta nossa condição humana, pois qualquer película exibe fraturas que despertam fascínio pelo desconhecido. $\mathrm{O}$ 
resultado demonstra a potencialidade desses filmes para a produção de conhecimento atrelada à produção de subjetividade na educação contemporânea.

Todavia, o Universo é maior do que se evidencia um testemunho qualquer. Segredo de ilê-axé resguarda-se pra sempre...

$$
\text { Recebido em: 27-02-2019 Aceito em: 11-03-2019 }
$$

\section{Referências}

CANCLINI, N. G. O mundo inteiro como lugar estranho. São Paulo: EdUSP, 2016.

EAGLETON, T. A morte de Deus na cultura. Rio de Janeiro: Record, 2016.

GARCIA, W. Corpo, mídia e representação: estudos contemporâneos. São Paulo, Pioneira Thomson Learning, 2005.

GIANNETTI, E. Trópicos utópicos. São Paulo: Cia das Letras, 2016.

GUMBRECHT, H. U. Nosso amplo presente: o tempo e a cultura contemporânea. São Paulo: Unesp editora, 2015.

HALL, S. Cultura e representação. Rio de Janeiro: PUC-Rio : Apicuri, 2016.

PELBART, P. P. O avesso do niilismo: cartografias do esgotamento. São Paulo: n-1 edições, 2013.

POVÓAS, R. de C. A viagem de Orixalá: estrada de sagitário, caminhos de Orumilá. Ilheus: Editus, 2015.

SODRÉ, M. A ciência do comum: notas para o método comunicacional. São Paulo: Martins Fontes, 2014.

VILLAÇA, N. O consumo da cultura: comunicação e performance. São Paulo: Cores e Letras, 2018.

ŽIŽEK, S. Acontecimento: uma viagem filosófica através de um conceito. Rio de Janeiro: Zahar, 2017. 